\title{
Design considerations for community-based stream monitoring to detect changes in Pacific salmon habitats
}

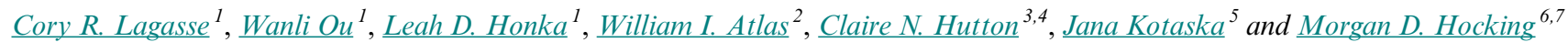

\begin{abstract}
Communities in the Great Bear Rainforest of British Columbia, Canada are highly dependent on Pacific salmon (Oncorhynchus spp.) and the watersheds that support them, yet current monitoring efforts are likely inadequate for detecting changes in stream habitats that may affect salmon populations. The Coastal First Nations Regional Monitoring System is attempting to address these information gaps through a new stream assessment program that collects baseline information and tracks changes in stream habitats. Using the program's monitoring protocol, we assessed the habitat characteristics of eight streams within the Koeye and Namu watersheds, then used a statistical power simulation to determine within-stream sampling requirements for detecting changes in substrate composition that may affect salmon habitat suitability. We also assessed resource constraints and perceived threats to stream habitats via questionnaires to coastal First Nations' stewardship staff. Results suggest that the current recommended sample size of 6 withinstream transects has low statistical power for detecting biologically significant changes in fine sediment. Given limited monitoring resources, we recommend higher transect sampling intensities within productive riffle-pool streams, but an emphasis on monitoring site level characteristics, such as large woody debris and pool volume, in less productive, high gradient cascade-pool streams. Questionnaire results highlight the need for flexibility and local adaptation in monitoring efforts because of differences in resource constraints among First Nations communities. If successfully implemented, the stream assessment program can integrate local knowledge with western science to inform ecosystem-based management of watersheds within the Great Bear Rainforest.
\end{abstract}

Key Words: adaptive governance; ecosystem-based management; First Nations management; Great Bear Rainforest; Pacific salmon; power analysis; stream monitoring

\section{INTRODUCTION}

Streams and riparian habitats are ecologically important landscape components that provide a wide range of ecosystem services (Naiman et al. 1993, Jones et al. 2010, Naiman and Dudgeon 2011). In the Pacific Northwest, the well-being of many First Nation communities is intrinsically linked to the ecosystem services provided by stream habitats because they sustain the distribution, abundance, and diversity of Pacific salmon (Oncorhynchus spp.) populations (Stouder et al. 1997, Bottom et al. 2009, Campbell and Butler 2010). However, anthropogenic impacts can broadly reduce ecosystem services provided by streams (Sweeney et al. 2004, Naiman and Dudgeon 2011), including the degradation and loss of freshwater habitat, which has been implicated in declines of Pacific salmon populations (NRC 1996, Slaney et al. 1996). As one of the largest tracts of intact temperate rainforest in the world, the Great Bear Rainforest (GBR) of British Columbia (BC), Canada, contains a richness and diversity of stream habitats that support over 2500 salmon runs (Temple 2005). Changes in streams and riparian habitats are therefore of particular concern for communities in the GBR (Temple 2005) because of their strong connection with Pacific Salmon.

As concerns for salmon stream health have heightened, so has recognition of First Nations rights (Garner and Parfitt 2006). In the past few decades, First Nations in $\mathrm{BC}$ have been regaining management authority over resources in their territories, catalyzed in part by successful Aboriginal rights and title court cases in the 1990s and ongoing treaty and nontreaty negotiations. This has enabled the initiation of an ecosystem-based management (EBM) system in the GBR that is a result of land use planning and government-to-government agreements signed between the province of BC and coastal First Nations (Price et al. 2009). The EBM framework within the GBR reflects an adaptive governance approach, i.e., the integration of different types of knowledge through open decision-making structures operating at multiple scales (Brunner et al. 2005, Olsson et al. 2006). The initiative includes Provincial and First Nations government-to-government negotiation, broad coalitions among stakeholders, and consensus-based land-use decisions that recognize both ecological integrity and human well-being (Price et al. 2009). By connecting individuals, organizations, and institutions at multiple scales, EBM aims to manage human activities to ensure the coexistence of healthy, fully functioning ecosystems and human communities (Dietz et al. 2003, Fenger et al. 2009). However, despite statements of public support for EBM from federal and provincial governments (BCMAL 2006), current resource allocation toward monitoring is likely insufficient to effectively monitor the outcomes of EBM in the GBR, especially for remote watersheds and salmon-bearing streams (Price et al. 2008).

To address these shortcomings, a number of First Nations have begun monitoring within their own territories as part of a broader Coastal First Nations Regional Monitoring System (RMS) that was developed by the Coastal Stewardship Network (Kotaska 2013). The Coastal Stewardship Network is a project of the Coastal First Nations - Great Bear initiative that supports First Nation stewardship offices by coordinating priority regional projects, providing training, and creating outreach and resource

\footnotetext{
${ }^{1}$ School of Resource and Environmental Management, Simon Fraser University, ${ }^{2}$ Qqs Projects Society, ${ }^{3}$ Independent Resource Management Consultant, ${ }^{4}$ TNC Canada, ${ }^{5}$ Institute for Resources, Environment and Sustainability, University of British Columbia, ${ }^{6} \mathrm{Hakai}$ Network for Coastal People, Ecosystems and Management, Simon Fraser University, ${ }^{7}$ School of Environmental Studies, University of Victoria
} 
materials. The RMS was developed based on priorities articulated by stewardship offices to facilitate the collection, ownership, and analysis of data that will aid in local resource management.

The RMS includes a recently introduced stream assessment program, a procedure for standardized data collection to monitor stream habitats and salmon populations. Monitoring stream conditions enables the tracking of watershed responses to habitat alterations (Larsen et al. 2004), assists in prioritizing areas for conservation (Pess et al. 2002, Braun and Reynolds 2011), and provides baseline information on habitat quality and population abundance of salmon (Price et al. 2008), all of which can contribute to EBM within the GBR. Ideally, RMS stream assessments would allow each First Nation to collect widespread, intensive, and statistically rigorous data on streams throughout their territory. However, limited financial, personnel, and time resources means that the stream assessment program must optimize limited sampling resources. To achieve this, monitoring objectives should be used to guide monitoring protocol (MacDonald et al. 1991, MacDonald and Smart 1993), such as the selection of cost-effective variables for measurement (Braun and Reynolds 2012) and the number of samples needed to produce statistically rigorous results (Ladson et al. 2006).

The main objectives of the habitat assessment component of the RMS stream monitoring program are to collect baseline information on stream habitat quality and monitor for changes over time, however, the specific monitoring objectives and priorities may vary according to the needs and concerns of each First Nation community. Potential threats to stream ecosystems within each First Nation's territory will be a key consideration for monitoring design. Apart from possible overharvest of salmon which can affect terrestrial ecosystems (Darimont et al. 2010, Hocking and Reynolds 2011), there are three main risks to stream ecosystem functioning in the GBR: (1) vegetation removal and road construction from forest harvesting under EBM (e.g., Tschaplinski and Pike 2010); (2) other watershed developments, such as from liquefied natural gas, mining, or crude oil projects (e.g., Service et al. 2012); and (3) climate change (e.g., Battin et al. 2007).

In this study, we collected information on stream physical properties within two ecologically and culturally significant watersheds of the GBR, the Koeye and Namu rivers, to provide advice on optimizing monitoring protocols in consideration of threats to stream habitats within the GBR, statistical power, and community resource constraints. We provide recommendations on within-stream sample sizes by estimating statistical power to detect changes in percent fine sediments and median particle size, two important metrics of substrate suitability for salmon. We complement these recommendations with questionnaires completed by coastal First Nations stewardship staff to assess perceived threats to stream habitats, current stream monitoring efforts, and resource limitations for First Nations stewardship offices.

\section{METHODS}

\section{Study area}

Our study sites are located in the Namu and Koeye watersheds, within the Great Bear Rainforest (Fig. 1). These watersheds represent two of the largest complexes of untouched ancient rainforest on the Central Coast of $\mathrm{BC}$ with cultural and ecological importance to the local First Nations (HTC 2005, Brown and Brown 2009). Selection of streams for assessment consisted of a hierarchical sampling design, with transects nested within streams and four stream sites nested within each watershed. Three channel types were assessed: four small, low gradient, riffle-pool streams (referred to as Namu 1, 2, 3, and Koeye 1), two small, high gradient, cascade-pool streams (Koeye 2 and 3), and two large, low gradient channels that are part of the upper Namu River and Koeye River (Namu main and Koeye main).

Fig. 1. Location of stream assessment sites within the Koeye and Namu watersheds of the Great Bear Rainforest, British Columbia.

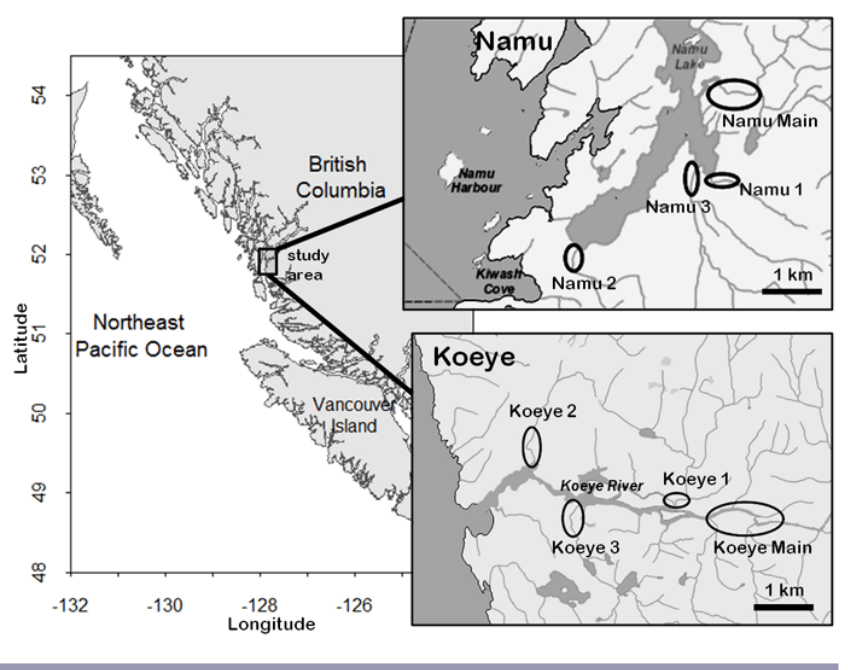

\section{Stream habitat characteristics}

We measured reach and transect level characteristics at the eight stream sites based on the preliminary data collection procedure of the RMS stream assessment program (Fig. 2; Appendix 1). The reach length for each stream site was defined as 10 times the bankfull width. For every reach, we categorized the stream type, measured percent gradient, counted large pool or cover-forming woody debris (LWD) and visually estimated substrate embeddedness, stream discharge, and turbidity. We also measured percent pool length and pool volume using the residual pool depth multiplied by the length and width for all pools. Collectively, many of the characteristics measured may be used to assess stream suitability for salmon (Sharma and Hilborn 2001, Braun and Reynolds 2011).

A maximum sample size, or number of transects, was established by doubling the 6 transects per reach initially recommended by the RMS protocol. Thus, we spaced 12 transects evenly from the start to the end of the reach, with each transect placed perpendicular to the stream flow. For every transect, we measured bankfull width, maximum water depth, bankfull depth, open canopy width, and categorized if banks were undercut. We assessed substrate composition by measuring the intermediate axis length of 10 particles sampled at regular intervals along the wetted width of the transect. Particles were randomly selected from beneath the surveyor's foot to minimize selection bias as a 
result of particle size. Substrate composition is summarized using two measures: the percent of particles that are fine sediment, defined as particles smaller than $2 \mathrm{~mm}$, and the median length of particles for each transect, referred to as $\mathrm{D}_{50}$. Within-stream variability is summarized for each transect characteristic using the coefficient of variation, which represents the ratio of the standard deviation to the mean, with higher values indicating higher variability (Conquest 1983).

Fig. 2. Stream transect card used to record stream characteristics at multiple cross-sectional transects for the Regional Monitoring System (RMS) of the Coastal Stewardship Network. The RMS also includes a stream visit, stream assessment, and salmon escapement card, shown in Appendix 1. Transect cards were developed by the Coastal First Nations - Great Bear Initiative and reproduced with their permission.

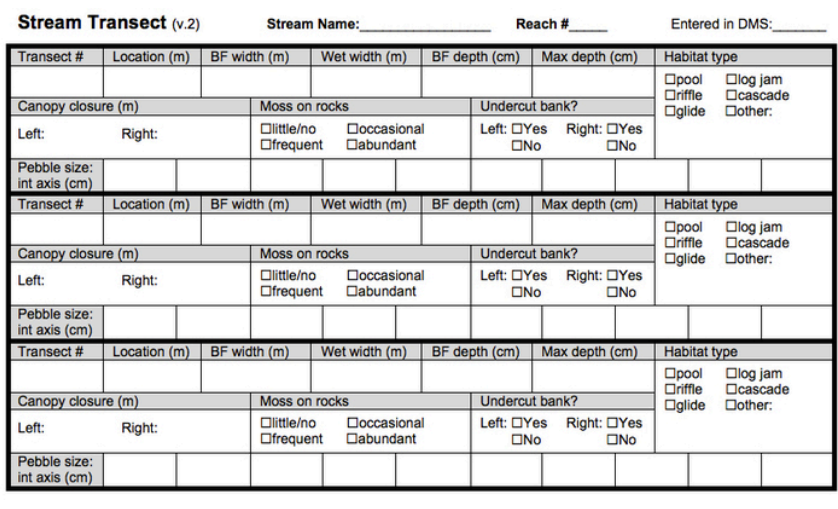

Power to detect changes in substrate composition

Detecting changes in stream habitats is an important component of the RMS stream assessment program. Therefore, we conducted a statistical power simulation to determine the relationship between the number of stream transects and the ability to detect changes in substrate composition when a stream is reassessed at some future time. Using simulation instead of a traditional power analysis can provide estimates of statistical power that are more robust and ecologically realistic (Bolker 2008). For our analysis, the minimum detectable effect (MDE) represents the minimum change in stream substrate that the sampling procedure would be able to detect statistically (MacDonald et al. 1991) using a statistical power ( 1 - type II error) of 0.8 and a significance level (type I error) of 0.05 .

We focused on $\mathrm{D}_{50}$ and percent fine sediment for our power analysis over other transect characteristics because these properties required time-consuming particle counts, and changes in these characteristics could have important ecological consequences. Increases in fine sediment concentrations may reduce the egg-fry survival and rearing success of salmonids (Suttle et al. 2004, Jensen et al. 2009), with threshold effects on egg-fry survival observed at 10 to 15 percent concentration of particles under $1 \mathrm{~mm}$ or $2 \mathrm{~mm}$ in length (Kondolf 2000, BCMOE 2001, Jensen et al. 2009). Because increases in fine sediment may occur following logging activities and road building (Scrivener and Brownlee 1989, Jackson et al. 2001, BCMOE 2001), detecting changes using before-after stream assessments will likely be an important monitoring objective for First Nations stewardship offices. $\mathrm{D}_{50}$ is indicative of substrate suitability for redd digging (Kondolf 2000), although no specific thresholds have been established relating to salmon habitat suitability.

To mimic data collection by future stream assessments, we simulated a second dataset of samples over a range of effect sizes and sample sizes for $\mathrm{D}_{50}$ and percent fine sediment. Sample values were generated for $\mathrm{D}_{50}$ by randomly sampling from a log-normal distribution with standard deviation equal to the observed value for that stream, and mean equal to the observed value plus an added effect size. For percent fine sediment, random samples were drawn from a binomial distribution with each sample representing 10 draws using a probability of success set to the observed proportion of fine sediment for that stream plus an effect size. The statistical significance of the effect size for $D_{50}$ was determined by the $p$-value of a t-test. Statistical significance for percent fine sediment was assessed by logistic regression using a bias correction for low numbers of successes (Firth 1993).

A thousand iterations of this simulation procedure were performed for each combination of effect size and sample size. The statistical power of the test was calculated based on the proportion of times that a p-value smaller than the significance level of 0.05 was obtained, representing whether or not the effect size was deemed statistically significant. The MDE for each sample size was then determined based on the effect size where statistical power was equal to or greater than 0.8 . We determines MDE values over a sample size range of 4 to 12 , representing a relatively low to high sampling intensity based on resource and time constraints of the CSN. For streams where this sample range failed to detect changes in fine sediment of $10 \%$, we determined the number of samples needed to detect this potential threshold value by increasing the sample size range. All analyses were done using R 2.15.1 (R Core Team 2012) and the brglm package for logistic regression with bias correction (Kosmidis 2013).

\section{Monitoring questionnaire}

To obtain information on the local context of monitoring priorities, resource constraints and current monitoring efforts, we surveyed stewardship office staff from several coastal First Nations involved with the RMS. The survey consisted of 11 questions, with 7 categorical and 4 open-ended questions. Specifically, we inquired about perceived threats to freshwater habitat, the adequacy of current stream monitoring, which institutions they thought should perform monitoring, resource constraints that will prohibit stream assessments, and if stream assessments would benefit their community. Questionnaires were given to stewardship staff members during the 2012 Annual Coastal Stewardship Network Gathering, two days after they had completed a training session on the stream assessment card methodology to ensure that they were familiar with the methodology and purpose of the program. We received 11 completed questionnaires out of 15 that were distributed.

\section{RESULTS}

\section{Stream habitat characteristics}

The natural variability in measured habitat properties was considerable within and among the eight pristine streams, however, variability was considerably lower for most 
Table 1. Reach level characteristics of the eight streams assessed in the Namu and Koeye watersheds. Large woody debris (LWD) density is given as the number of pieces per $10 \mathrm{~m}$ of reach length. Pool length is the percent of the reach length represented by pool habitats. Pool volume density is estimated based on the length $\mathrm{x}$ width $\mathrm{x}$ residual depth of all pools and averaged per $10 \mathrm{~m}$ of reach length. Pools were too deep to measure at Namu main and Koeye main.

\begin{tabular}{|c|c|c|c|c|c|c|c|}
\hline Stream & Channel type & $\begin{array}{l}\text { Wetted width } \\
(\mathrm{m})\end{array}$ & $\begin{array}{l}\text { Reach length } \\
\text { (m) }\end{array}$ & Gradient $(\%)$ & Pool length (\%) & $\begin{array}{c}\text { Pool volume } \\
\left(\mathrm{m}^{3} / 10 \mathrm{~m}\right)\end{array}$ & LWD (pieces/10m) \\
\hline Namu 1 & Riffle-pool & 5.1 & 81 & 2.5 & 54.1 & 13.43 & 5.43 \\
\hline Namu 2 & Riffle-pool & 7.6 & 84 & 2 & 49.1 & 6.58 & 4.38 \\
\hline Namu 3 & Riffle-pool & 4.9 & 86 & 1 & 50.3 & 12.83 & 7.79 \\
\hline Koeye 1 & Riffle-pool & 7.5 & 88 & 2 & 22.1 & 2.83 & 2.05 \\
\hline Koeye 2 & Cascade-pool & 5.4 & 82 & 22.5 & 27.7 & 4.24 & 4.66 \\
\hline Koeye 3 & Cascade-pool & 6 & 66 & 10 & 15.0 & 1.77 & 1.36 \\
\hline Namu main & Large channel & 17.4 & 174 & 1 & - & - & 4.83 \\
\hline Koeye main & Large channel & 35.5 & 520 & 3 & - & - & 0.19 \\
\hline
\end{tabular}

characteristics when the same channel types were compared (Tables 1 and 2). Riffle-pool streams shared many characteristics including a low percent gradient (range of 1 - 2.5), small median particle size $\left(\mathrm{D}_{50}\right.$ range of $\left.1.1-3.0 \mathrm{~cm}\right)$, high percentage of banks undercut (range of 50-75\%), and a generally high percent pool length (mean of $43.9 \%$ ). Cascade-pool streams had a high percent gradient (10 and 22.5), large $\mathrm{D}_{50}(19.8$ and $22.0 \mathrm{~cm})$, low percentage of banks undercut (13 and $8 \%$ ), and low percent pool length (28 and 15\%), although only two streams of this type were assessed. Most streams had a high density of LWD with a mean of 3.8 pieces per 10 meters of reach length counted across all streams.

We observed high variability, as demonstrated by coefficient of variation values, for many of the transect-level characteristics within streams, such as bankfull width, open canopy width, and $\mathrm{D}_{50}$ (Table 2). The average coefficient of variation values over all streams for bankfull width, open canopy width and $\mathrm{D}_{50}$ were 0.31 , 1.23 , and 0.61 respectively. Fine sediment varied from $0 \%$ to $38 \%$, with the lowest values of $0 \%$ and $2 \%$ in cascade-pool streams and higher percentages observed in riffle-pool streams and Namu main.

\section{Power to detect changes in substrate composition}

The minimum detectable effect (MDE) for fine sediment varied among streams, however, MDE was similar within channel types. MDE for fine sediment ranged from $22 \%$ to $27 \%$ using 4 samples and declined with 12 samples to a range of $8 \%$ to $16 \%$ (Fig. 3A). Fine sediment MDE was lower in cascade-pool streams than in riffle-pool streams, with averages of $8.6 \%$ and $14.3 \%$ respectively, using a sample size of 12 . These differences occur because observed fine sediment concentrations were low in cascade-pool streams, and increases in proportions that begin closer to zero are easier to detect on the logit scale. To detect changes in percent fine sediment equal to a threshold of 10\% (BCMOE 2001), sample sizes of 18 to 23 transects would be needed in riffle-pool streams and 28 transects for Namu main. However, observed values for fine sediment were already above 10 percent in these streams.

MDE values for $\mathrm{D}_{50}$ were also variable among streams, but again variability was lower within riffle-pool and cascade-pool channel types (Fig. 3B). Low MDE $D_{50}$ values were consistently estimated for riffle-pool streams; MDE values were no greater than $3.0 \mathrm{~cm}$ with a sample size of 4 and $1.3 \mathrm{~cm}$ with a sample size of 12 . In
Fig. 3. Minimum detectable effect (MDE) size for percent fine sediment (Panel A) and median particle size, or D50 (Panel B), as a function of sample size with statistical power of 0.8 and significance level of 0.05 . Lines with grey points represent low gradient riffle-pool streams, black points represent high gradient cascade-pool streams, and white points indicate large, low gradient streams. D50 results for Koeye 1, Namu 3, and Namu main are combined under Namu 1 and Namu 2, respectively, because nearly identical MDE values were obtained. The MDE for Koeye Main could be predicted up to $\mathrm{n}$ $=7$ because only seven transects could be completed at that stream.

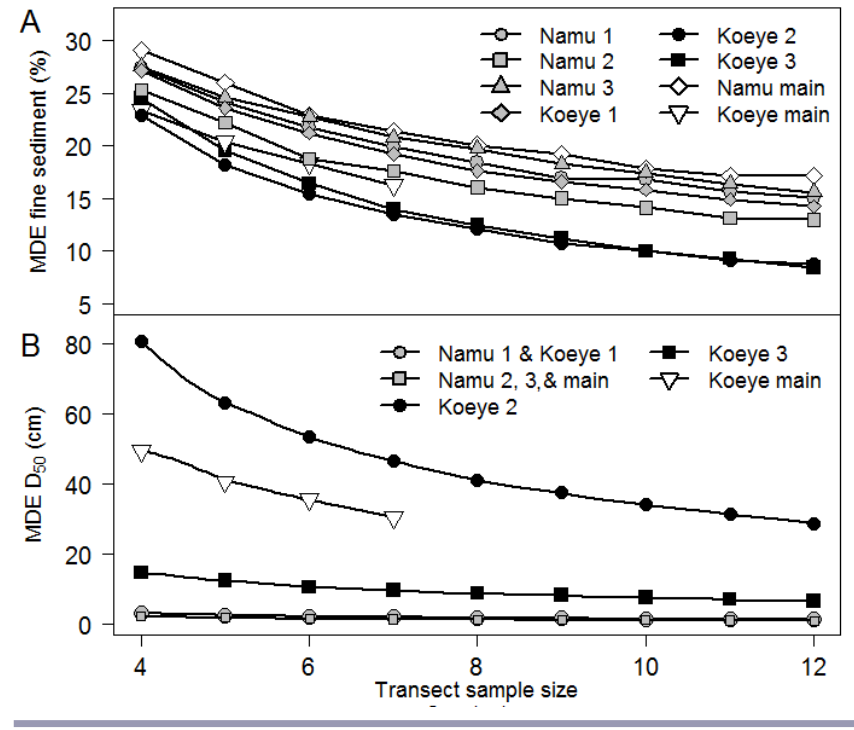

contrast, cascade-pool streams had much higher MDEs, with values of 19.0 to $78.5 \mathrm{~cm}$ obtained using four samples, and 7.5 to $28.5 \mathrm{~cm}$ with a sample size of 12 .

Monitoring questionnaire

The 11 respondents to our questionnaire represented stewardship office staff in 6 different coastal First Nations communities, including the Heiltsuk (Bella Bella), Metlakatla (Prince Rupert), Wuikinuxw (Rivers Inlet), Haisla (Kitamat Village), Gwa'sala- 
Table 2. Summary of the transect level characteristics for each stream. Reported values represent the average over all transects within a stream with coefficient of variation values given within brackets. Fine sediment represents the percentage of particles with intermediate axis length less than $2 \mathrm{~mm}$ over all particles counted within a stream, and therefore no standard deviation value is given. Banks undercut represents the percentage of undercut banks over all transects within a stream.

\begin{tabular}{|c|c|c|c|c|c|c|c|}
\hline Stream & Bank width (m) & $\begin{array}{c}\text { Bankfull depth } \\
\text { (cm) }\end{array}$ & $\begin{array}{l}\text { Water depth } \\
(\mathrm{cm})\end{array}$ & Open canopy (m) & $\mathrm{D}_{50}(\mathrm{~cm})$ & $\begin{array}{c}\text { Fine sediment } \\
(\%)\end{array}$ & $\begin{array}{c}\text { Banks } \\
\text { undercut }(\%)\end{array}$ \\
\hline Namu 1 & $9.3(0.44)$ & $81(0.25)$ & $44(0.49)$ & $2.6(1.1)$ & $2.9(0.41)$ & 20 & 50 \\
\hline Namu 2 & $7.6(0.35)$ & $62(0.51)$ & $35(0.74)$ & $0.8(2.0)$ & $2.7(0.30)$ & 10 & 75 \\
\hline Namu 3 & $10.2(0.32)$ & $106(0.43)$ & $54(0.58)$ & $0.4(2.7)$ & $1.1(0.76)$ & 26 & 63 \\
\hline Koeye 1 & $7.5(0.38)$ & $56(0.27)$ & $26(0.39)$ & $2.0(0.80)$ & $3.0(0.39)$ & 17 & 54 \\
\hline Koeye 2 & $8.6(0.13)$ & $62(0.23)$ & $27(0.42)$ & $4.5(1.3)$ & $22.0(1.27)$ & 2 & 13 \\
\hline Koeye 3 & $7.8(0.26)$ & $80(0.18)$ & $37(0.35)$ & $2.5(0.69)$ & $19.8(0.31)$ & 0 & 8 \\
\hline Namu main & $22.3(0.21)$ & $155(0.15)$ & $111(0.19)$ & $8.6(0.82)$ & $1.1(0.66)$ & 38 & 42 \\
\hline Koeye main & $36.3(0.38)$ & $167(0.22)$ & $120(0.38)$ & $27.3(0.45)$ & $26.9(0.80)$ & 7 & 21 \\
\hline
\end{tabular}

'Nakwaxda'xw (Port Hardy), and Nuxalk (Bella Coola) Nations. Roles and responsibilities of the stewardship staff were diverse, including monitoring, patrolling, administration, fisheries technician, and management. Therefore, our results represent a broad cross-section of stewardship staff and coastal First Nation communities.

The most commonly identified threat to salmon streams was logging, which was listed in 8 of the 11 responses (Fig. 4A). Other identified threats included landslides (3 respondents), climate change ( 2 respondents), flooding (2 respondents), and LWD removal during the late 1970s to the 1980s (1 respondent). Of 11 respondents, 7 disagree or strongly disagree that current stream monitoring by Fisheries and Oceans Canada (DFO) is adequate (Fig. 5A). Nine respondents agreed or strongly agreed that a stream assessment program would be beneficial to their community (Fig. 5B), and 8 respondents agreed or strongly agreed

Fig. 4. Responses to open-ended and ranking questions of our Coastal Stewardship Network questionnaire. Panel A responses were open-ended, though the majority of respondents listed logging as the main threat. Panel B shows the primary and secondary ranked limiting factors for conducting stream assessments, chosen from a list of eight options. Some respondents ranked more than one factor as the primary limiting factor, resulting in more than 11 responses. LWD = large pool or cover-forming woody debris.
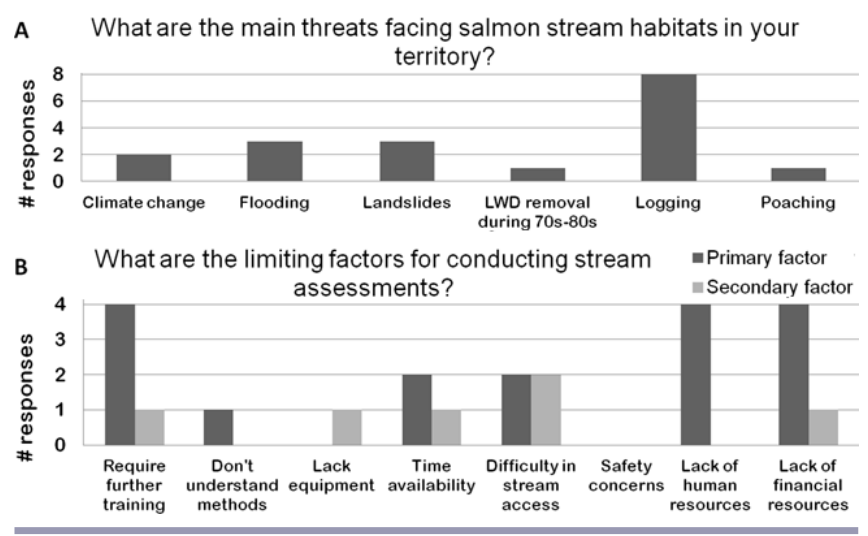

that they would like to see a standardized stream assessment training program or trainer (Fig. 5C). Of 11 respondents, 8 prefer that the local stewardship office and DFO collaborate on assessments, while 3 respondents prefer only the local First Nation stewardship office perform assessments (Fig. 5D). The amount of time and personnel resources available to perform stream assessments per month was variable, as 1 day or less, 2 to 4 days and 8 days each received 3 responses (Fig. 5E), while staff availability ranged from 0 to 6 (Fig. $5 \mathrm{~F}$ ). Lack of human resources, lack of financial resources, and a need for further training were stated as the 3 primary factors limiting stream monitoring, followed by time availability and difficulty in accessing streams (Fig. 4B).

Fig. 5. Responses to the categorical questions of our Coastal Stewardship Network questionnaire. We received 11 responses for every question. DFO = Fisheries and Oceans Canada.

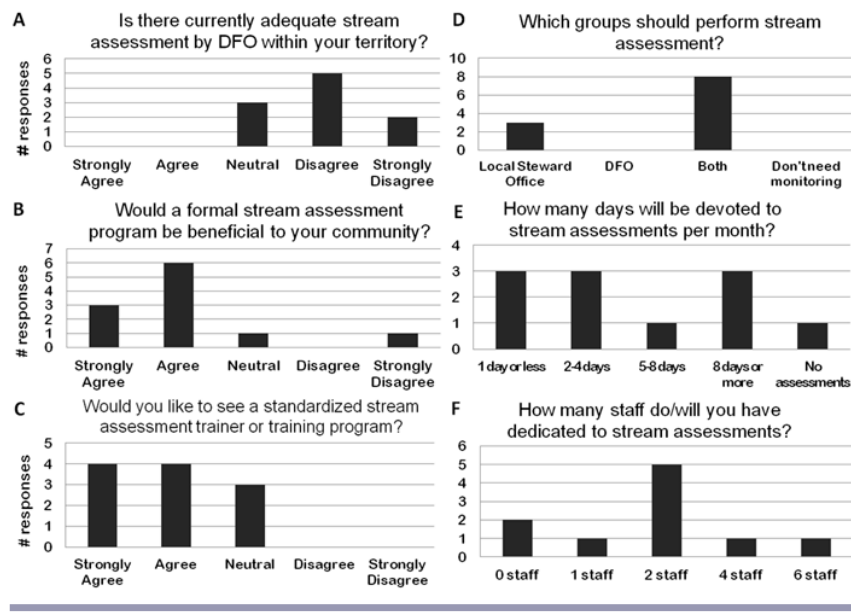

\section{DISCUSSION}

\section{Stream monitoring recommendations}

Our recommendations for within-stream sampling draw upon the results of our stream assessments and power analysis, as well as information from our qualitative survey highlighting the resource constraints to First Nations communities and perceived threats 
to stream habitats. Forest harvesting was identified as the main threat to streams by a large majority of stewardship staff, and is one of the main threats to streams within the GBR (Tschaplinski and Pike 2010, Hocking et al. 2013). Therefore, detecting changes in stream habitats associated with logging activities should be an important monitoring objective. These changes are dependent on forestry practices and stream morphology, but may include sediment loading, bank erosion, and decreases in pool volume and LWD density (Hartman et al. 1996, Gomi et al. 2005, Mellina and Hinch 2009).

Estimated MDE values for percent fine sediment suggest that before-after site visits using transect particle counts are unlikely to detect biologically significant increases in fine sediment over the range of sample sizes examined. Even with 12 transects, particle counts may not detect increases in fine sediment of $15 \%$ in riffle-pool streams and $9 \%$ in cascade-pool streams. As a result, fine sediment concentrations may exceed recommended guidelines of $10 \%$ to $15 \%$ before any changes are detected, reducing egg-fry survival and rearing success of salmonids (Kondolf 2000, BCMOE 2001, Suttle et al. 2004, Jensen et al. 2009). Additionally, MDE values are larger within streams that contain elevated fine sediment concentrations, such as Namu main and Namu 3, suggesting it will be difficult to detect fine sediment increases for streams where even small increases may negatively impact salmon habitat. On the other hand, MDE values for $\mathrm{D}_{50}$ are low in the same streams with high fine sediment, indicating that other changes in substrate composition may be detected within the range of transect sample sizes examined.

We suggest adjusting within-stream sampling intensity and methods based on channel type to optimize monitoring efforts. The small to medium-sized riffle-pool streams in our study area possess many of the characteristics of productive salmon habitat, such as a high pool volume, undercut banks, and coarse gravel substrate (Sharma and Hilborn 2001, Braun and Reynolds 2011), therefore, these streams would be a priority for detecting changes. MDE values for fine sediment do not decline below $10 \%$ unless 18 to 23 transects are conducted within riffle-pool streams, however, this sampling intensity may not be practical for each stream visit given personnel and time constraints. Therefore, instead of performing more than 12 transects we recommend measuring 30 particles per transect instead of 10 in riffle-pool streams. Within-stream variability in substrate composition may also be reduced if transects are stratified or targeted by habitat type. For example, performing particle counts exclusively on riffle habitat types within streams may increase statistical power for detecting changes (MacDonald et al. 1991), although this trend was not apparent in the streams we assessed. For cascade-pool streams, we do not recommend expending monitoring effort on transect particle counts beyond the initial site visit because these streams are unlikely to be habitats of high salmon productivity and may flush fine sediment because of the high gradient (Gomi et al. 2005). For large channel streams, logistical challenges of deep, fast moving water make intensive transect sampling hazardous and time consuming, therefore, we recommend that the RMS protocol for monitoring large streams and rivers should prioritize in-situ data loggers that can continuously measure stream flow and water quality.

Overall, the high natural variability observed within and among streams indicates that statistical detection of changes will be difficult without high sampling intensities. However, the baseline information collected by initial stream assessments will be valuable in characterizing the remote streams of the GBR, many of which have never been previously assessed. Therefore, beyond initial site visits, transects may not be the most efficient use of monitoring resources for detecting changes from logging or other disturbances, unless the stream is a high monitoring priority. In many cases, monitoring efficiency may be improved by focusing on the most cost-effective and ecologically important variables, such as LWD and pool volume (Braun and Reynolds 2012). Monitoring information can also be efficiently collected by methods that are not quantitative, such as repeated photographs over time of specific habitat features (MacDonald and Smart 1993), or site visits to detect both natural and anthropogenic disturbances such as landslides and road crossings.

Our results and recommendations should be taken in consideration of the assumptions of our statistical power simulation and data collection procedure. MDE estimates use only one level of statistical power and significance level ( 0.8 and 0.05 , respectively) based on statistical convention. Our analysis assumes that the standard deviation for $\mathrm{D}_{50}$ was identical for the observed and simulated data, however, events that affect $\mathrm{D}_{50}$ values may affect the variance of particle size distributions as well, thus influencing MDE values. The simulation method only compared two time-periods, however, if streams are continually monitored the power to detect trends will increase as more years of data are collected (Larsen et al. 2004). Additionally, our sample sites consisted of reaches of only 10 bankfull widths among 8 streams and 2 watersheds, therefore, we were likely unable to capture the full range of variability in substrate composition and stream types of the GBR. Despite these limitations, we expect that our power analysis provides reasonable estimates of minimum sample sizes needed to detect changes in substrate between two sampling periods.

\section{Broader sampling considerations}

Our sample size recommendations focus on the sampling intensity within streams, however, successfully monitoring stream habitats over large areas requires consideration of the broader spatial distribution of sampling effort within and among watersheds (Hughes and Peck 2008). There are inherent trade-offs between the number of streams or watersheds that can be assessed and the sampling intensity within each stream (Dobbie et al. 2008), especially because time and personnel resources were both identified by stewardship staff as major limitations to monitoring efforts. Ultimately, within-reach sampling intensities may be affected by the extent of each First Nation's territory and their monitoring capacity, which varies among stewardship offices. Although it is beyond the scope of this study to determine the appropriate distribution of sampling effort within the nested scales of the GBR, a well-designed hierarchical sampling plan could greatly contribute to the success of the RMS stream monitoring program.

There will be many considerations for the sampling plans of RMS stream monitoring, including the specific goals and capacity of each First Nations community, land-use plans under EBM, watershed attributes including current or future threats, accessibility for sampling, and statistical rigor. Stream monitoring plans should consider the EBM framework of the GBR because this will determine land-use activities such as the percentage of a 
watershed that can be clear-cut at one time (also called equivalent clear-cut area) or the width of riparian forest buffering. Although all the streams we assessed were located within conservancy areas, monitoring within nonconservancy areas that may be impacted by logging or other activities will likely be an important priority for First Nations. There is considerable uncertainty around the effects of forest management under EBM on streams and salmon in the GBR, suggesting a need for large-scale across-watershed monitoring of stream functioning that incorporates land-use activities, watershed attributes, and human well-being (Fenger et al. 2009, Hocking et al. 2013). Therefore, information collected by RMS stream monitoring could reduce this uncertainty and improve our understanding of the impacts of different land-use activities under EBM.

\section{Monitoring and ecosystem-based management}

The RMS stream assessment program, implemented within an EBM approach, connects individuals, organizations, agencies, and institutions at multiple levels (Folke et al. 2005), and employs various knowledge systems and experiences (Dietz et al. 2003). The assessment program draws on local knowledge systems and experiences by allowing each coastal First Nation the flexibility to set local monitoring objectives and priorities, yet monitoring will be conducted using a standardized sampling framework. A standardized framework will allow information to be used for broad comparisons and trend detection (Roper et al. 2010), while local adaptation can integrate local knowledge and understanding of watersheds into the detection of environmental change. This may improve monitoring effectiveness because local stewards and resource-users are more likely to be attuned to the complexity of their ecological systems (Moller et al. 2004, Berkes et al. 2007). The RMS stream assessments may thus contribute valuable information toward successful EBM of watersheds, while demonstrating the potential of combining local knowledge systems with scientific knowledge to cope with change in ecosystem management (Folke et al. 2005, Berkes et al. 2007).

The potential effectiveness of stream monitoring under the RMS will inevitably be limited by resource availability for monitoring, as highlighted by the results of our questionnaire. Currently, each Coastal First Nation is responsible for funding monitoring activities within their own territories and securing funding may be challenging. Funding for stewardship offices comes from various sources, including own source revenue, resource revenue sharing, and other agreements with the provincial government, federal government, and philanthropic foundations (COF 2010, Smith and Sterritt [date unknown]). Additionally, under Canadian law jurisdiction for habitat management is shared between provincial and federal governments, who have yet to fully recognize the political rights of First Nations to self-govern and enforce regulations within their traditional territories (Smith and Sterritt [date unknown]). The current system therefore creates imbalances between governance authority, resource revenue collection, and monitoring responsibilities. Given the lack of resources from both Crown governments and the current inability of First Nations to legally enforce regulations within their territories, the effectiveness of long-term monitoring in the GBR is uncertain. Monitoring efforts would likely be more sustainable if First Nations are able to access more funds to support resource management from the development of resources in their territories, either directly from industry or through more equitable resource revenue sharing with Crown governments (CCIRA [date unknown]).

Much uncertainty surrounds the future of the GBR, a landscape characterized by shifting governance and management regimes, low monitoring capacities, and risks to salmon populations and watersheds. However, these situations have provided opportunities for First Nations to assert their governance authority and improve resource stewardship. On an operational level, the RMS stream assessment program will facilitate knowledge acquisition, which is necessary for learning in the face of uncertainty and change. On an institutional level, the EBM approach seeks to manage human activities through the collaboration and reconciliation of diverse values and perspectives. The implementation of the RMS assessment program within EBM provides an example of adaptive governance, where flexible social management systems and institutions operate on scales that are appropriate to the challenges faced, to ultimately improve the management of uncertainties inherent in complex social-ecological systems.

Responses to this article can be read online at: http://www.ecologyandsociety.org/issues/responses. $\mathrm{php} / 6976$

\section{Acknowledgments:}

Funding for this research was provided by the Hakai Beach Institute and Simon Fraser University's Vice President Academic and Faculty of Environment's Collaborative Teaching Fellows Program. This study was completed as part of Simon Fraser University's Summer 2012 field course on Social-Ecological Resilience, held at the Hakai Beach Institute, on Heiltsuk and Wuikunuxv traditional territory. Claire Hutton was working on contract with Coastal First Nations - Great Bear Initiative during the course of this research and coordinated the Coastal Guardian Watchmen I Stewardship Network and associated projects. We are grateful to the Heiltsuk and Wuikunuxv First Nations for welcoming us to their territories, and thank our colleagues at Simon Fraser University for all their hard work in the field. We give special acknowledgement to the individuals who have provided inspiration and given important guidance during this study, including Anne Salomon, Brendan Connors, Jordan Rosenfeld, Sandra Thomson, William Housty, and all the Coastal Guardian Watchmen who participated in the qualitative portion of our study.

\section{LITERATURE CITED}

Battin, J., M. W. Wiley, M. H. Ruckleshaus, R. N. Palmer, E. Korb, K. K. Bartz, and H. Imaki. 2007. Projected impacts of climate change on salmon habitat restoration. Proceedings of the National Academy of Sciences 104:6720-6725. http://dx.doi.org/10.1073/ pnas.0701685104

Berkes, F., M. K. Berkes, and H. Fast. 2007. Collaborative integrated management in Canada's North: the role of local and traditional knowledge and community-based monitoring. Coastal Management 35:143-162. http://dx.doi.org/10.1080/08920750600970487 
Bolker, B. 2008. Ecological models and data in R. Princeton University Press, Woodstock, UK.

Bottom, D. L., K. K. Jones, C. A. Simenstad, and C. L. Smith. 2009. Reconnecting social and ecological resilience in salmon ecosystems. Ecology and Society 14(1): 5. [online] URL: http:// www.ecologyandsociety.org/vol14/iss1/art5/

Braun, D. C., and J. D. Reynolds. 2011. Relationships between habitat characteristics and breeding population densities in sockeye salmon (Oncorhynchus nerka). Canadian Journal of Fisheries and Aquatic Sciences 68:758-767. http://dx.doi. org/10.1139/f2011-015

Braun, D. C., and J. D. Reynolds. 2012. Cost-effective variable selection in habitat surveys. Methods in Ecology and Evolution 3:388-396. http://dx.doi.org/10.1111/j.2041-210X.2011.00154.x

British Columbia Ministry of Agriculture and Lands (BCMAL). 2006. News release: Province announces a new vision for coastal $B$. $C$. British Columbia Ministry of Agriculture and Lands, Victoria, British Columbia, Canada. [online] URL: http://www2.news.gov. bc.ca/news releases 2005-2009/2006AL0002-000066.htm

British Columbia Ministry of Environment (BCMOE). 2001. Water quality: ambient water quality guidelines (criteria) for turbidity, suspended and benthic sediments. British Columbia Ministry of Environment, Victoria, British Columbia, Canada. [online] URL: http://www.env.gov.bc.ca/wat/wq/BCguidelines/ turbidity/turbidity.html\#

Brown, F., and Y. K. Brown, compilers. 2009. Staying the course, staying alive - coastal First Nations fundamental truths: biodiversity, stewardship and sustainability. Biodiversity BC, Victoria, British Columbia, Canada. [online] URL: http://www. biodiversitybc.org/assets/Default/BBC Staying the Course Web. pdf

Brunner, R., T. A. Steelman, L. Coe-Juell, C. M. Cromley, C. A. Edwards, and D. W. Tucker. 2005. Adaptive governance: integrating natural resource science, decision making and policy. Columbia University Press, Chichester, New York, USA.

Campbell, S. K., and V. L. Butler. 2010. Archaeological evidence for resilience of Pacific Northwest salmon populations and the socioecological system over the last 7,500 years. Ecology and Society 15(1): 17. [online] URL: http://www.ecologyandsociety. org/vol15/iss1/art17/

Central Coast Indigenous Resource Alliance (CCIRA). [date unknown]. Planning: key issues. CCIRA, Bella Coola, British Columbia, Canada. [online] URL: http://ccira.ca/site/planning/ key-issues.html

Coast Opportunity Funds (COF). 2010. Weaving together the threads of conservation and community well-being. COF, Vancouver, British Columbia, Canada. [online] URL: http:// www.coastfunds.cal

Conquest, L. L. 1983. Assessing the statistical effectiveness of ecological experiments: utility of the coefficient of variation. International Journal of Environmental Studies 20:209-221. http:// dx.doi.org/10.1080/00207238308710037

Darimont, C. T., H. M. Bryan, S. M. Carlson, M. D. Hocking, M. MacDuffee, P. C. Paquet, M. H. H. Price, T. E. Reimchen, J.
D. Reynolds, and C. C. Wilmers. 2010. Salmon for terrestrial protected areas. Conservation Letters 3:379-389. http://dx.doi. org/10.1111/j.1755-263X.2010.00145.X

Dietz, T., E. Ostrom, and P. C. Stern. 2003. The struggle to govern the commons. Science 302:1907-1912. http://dx.doi.org/10.1126/ science. 1091015

Dobbie, M. J., B. L. Henderson, and D. L. Stevens. 2008. Sparse sampling: spatial design for monitoring stream networks. Statistics Surveys 2:113-153. http://dx.doi.org/10.1214/07-SS032

Fenger, M., S. Howard, S. Loo, and R. Holt. 2009. Adaptive management in experimental watersheds: research design. Mike Fenger and Associates Ltd., Victoria, British Columbia, Canada. [online] URL: http://www.for.gov.bc.ca/tasb/slrp/lrmp/nanaimo/ cencoast/ebmwg docs/am04a final report.pdf

Firth, D. 1993. Bias reduction of maximum likelihood estimates. Biometrika 80:27-38. http://dx.doi.org/10.1093/biomet/80.1.27

Folke, C., T. Hahn, P. Olsson, and J. Norberg. 2005. Adaptive governance of social-ecological systems. Annual Review of Environmental Resources 30:441-473. http://dx.doi.org/10.1146/ annurev.energy.30.050504.144511

Garner, K., and B. Parfitt. 2006. First Nations, salmon fisheries and the rising importance of conservation. Prepared for the Pacific Fisheries Resource Conservation Council, Vancouver, British Columbia, Canada. [online] URL: http://www.fish.bc.ca/files/ First $\% 20$ Nations $\% 20$ Salmon $\% 20$ Fisheries.pdf

Gomi, T., R. D. Moore, and M. A. Hassan. 2005. Suspended sediment dynamics in small forest streams of the Pacific Northwest. Journal of the American Water Resources Association 41:877-898. http://dx.doi.org/10.1111/j.1752-1688.2005.tb03775. $\underline{\mathrm{x}}$

Hartman, G. F., J. C. Scrivener, and M. J. Miles. 1996. Impacts of logging in Carnation Creek, a high-energy coastal stream in British Columbia, and their implication for restoring fish habitat. Canadian Journal of Fisheries and Aquatic Sciences 53 (S1):237-251. http://dx.doi.org/10.1139/cjfas-53-S1-237

Heiltsuk Tribal Council. 2005. Heiltsuk land use plan: for our children's tomorrows. Heiltsuk Tribal Council, Bella Bella, British Columbia, Canada [online] URL: http://www.firstnations.de/ media/04-1-land-use-plan.pdf

Hocking, M. D., S. M. O’Regan, R. P. White Collings, J. P. Benner, H. Munro, K. Squires, N. Swain, and K. Lertzman. 2013. Ecosystem-based management in the Great Bear Rainforest: a knowledge summary for priority ecological questions and experimental watersheds design. Prepared for the Coast Forest Region, BC Ministry of Forests, Lands and Natural Resource Operations. Hakai Network, Simon Fraser University, Burnaby, British Columbia, Canada.

Hocking, M. D., and J. D. Reynolds. 2011. Impacts of salmon on riparian plant diversity. Science 331:1609-1612. http://dx.doi. org/10.1126/science.1201079

Hughes, R. M., and D. V. Peck. 2008. Acquiring data for large aquatic resource surveys: the art of compromise among science, logistics, and reality. Journal of the North American Benthological Society 27:837-859. http://dx.doi.org/10.1899/08-028.1 
Jackson, C. R., C. A. Sturm, and J. M. Ward. 2001. Timber harvest impacts on small headwater stream channels in the Coast Ranges of Washington. Journal of the American Water Resources Association 37:1533-1549. http://dx.doi.org/10.1111/j.1752-1688.2001. $\underline{\mathrm{tb} 03658 . \mathrm{x}}$

Jensen, D. W., E. A. Steel, A. H. Fullerton, and G. R. Pess. 2009. Impact of fine sediment on egg-to-fry survival of Pacific Salmon: a meta-analysis of published studies. Reviews in Fisheries Science 17:348-359. http://dx.doi.org/10.1080/10641260902716954

Jones, K. B., E. T. Slonecker, M. S. Nash, A. C. Neale, T. G. Wade, and S. Hamann. 2010. Riparian habitat changes across the continental United States (1972-2003) and potential implications for sustaining ecosystem services. Landscape Ecology 25:1261-1275. http://dx.doi.org/10.1007/s10980-010-9510-1

Kondolf, G. M. 2000. Assessing salmonid spawning gravel quality. Transactions of the American Fisheries Society 129:262-281. http://dx.doi.org/10.1577/1548-8659(2000)129<0262:ASSGQ>2.0. $\underline{\mathrm{CO} ; 2}$

Kosmidis, I. 2013. brglm: Bias reduction in binary-response Generalized Linear Models. [online] URL: http://www.ucl.ac. $\underline{\text { uk/ ucakiko/software.html }}$

Kotaska, J. 2013. Reconciliation 'at the end of the day': decolonizing territorial governance in British Columbia after Delgamuukw. Dissertation, University of British Columbia, Vancouver, British Columbia, Canada. [online] URL: http://hdl. handle.net/2429/45003

Ladson, A. R., R. B. Grayson, B. Jawecki, and L. J. White. 2006. Effect of sampling density on the measurement of stream condition indicators in two lowland Australian streams. River Research and Applications 22:853-869. http://dx.doi.org/10.1002/ $\underline{\text { rra. } 940}$

Larsen, D. P., P. R. Kaufmann, T. M. Kincaid, and N. S. Urquhart. 2004. Detecting persistent change in the habitat of salmonbearing streams in the Pacific Northwest. Canadian Journal of Fisheries and Aquatic Sciences 61:283-291. http://dx.doi. org/10.1139/f03-157

MacDonald, L. H., and A. Smart. 1993. Beyond the guidelines: practical lessons for monitoring. Environmental Monitoring and Assessment 26:203-218. http://dx.doi.org/10.1007/BF00547499

MacDonald, L. H., A. W. Smart, and R. C. Wissmar. 1991. Monitoring guidelines to evaluate effects of forestry activities on streams in the Pacific Northwest and Alaska. EPA/910/9-91-001, NPS Section, U.S. EPA Region 10, Seattle, Washington, USA.

Mellina, E., and S. G. Hinch. 2009. Influences of riparian logging and in-stream large wood removal on pool habitat and salmonid density and biomass: a meta-analysis. Canadian Journal of Forest Research 39:1280-1301. http://dx.doi.org/10.1139/X09-037

Moller, H., F. Berkes, P. O. Lyver, and M. Kislalioglu. 2004. Combining science and traditional ecological knowledge: monitoring populations for co-management. Ecology and Society 9(3): 2. [online] URL: http://www.ecologyandsociety.org/vol9/ iss $3 / \operatorname{art} 2 /$
Naiman, R. J., H. Decamps, and M. Pollock. 1993. The role of riparian corridors in maintaining regional biodiversity. Ecological Applications 3:209-212. http://dx.doi.org/10.2307/1941822

Naiman, R. J., and D. Dudgeon. 2011. Global alteration of freshwaters: influences on human and environmental well-being. Ecological Research 26:865-873. http://dx.doi.org/10.1007/ s11284-010-0693-3

National Research Council (NRC). 1996. Upstream: salmon and society in the Pacific Northwest. National Academy Press, Washington, D.C., USA.

Olsson, P., L. H. Gunderson, S. R. Carpenter, P. Ryan, L. Lebel, C. Folke, and C. S. Holling. 2006. Shooting the rapids: navigating transitions to adaptive governance of social-ecological systems. Ecology and Society 11(1): 18. [online] URL: http://www. ecologyandsociety.org/vol11/iss1/art18/

Pess, G. R., D. R. Montgomery, E. A. Steel, R. E. Bilby, B. E. Feist, and H. M. Greenberg. 2002. Landscape characteristics, land use, and coho salmon (Oncorhynchus kisutch) abundance, Snohomish River, Washington, USA. Canadian Journal of Fisheries and Aquatic Science 59:613-623. http://dx.doi. org/10.1139/f02-035

Price, K., A. Roburn, and A. MacKinnon. 2009. Ecosystem-based management in the Great Bear Rainforest. Forest Ecology and Management 258:495-503. http://dx.doi.org/10.1016/j.foreco.2008.10.010

Price, M. H. H., C. T. Darimont, N. F. Temple, and S. M. MacDuffee. 2008. Ghost runs: management and status assessment of Pacific salmon (Oncorhynchus spp.) returning to British Columbia's central and north coasts. Canadian Journal of Fisheries and Aquatic Sciences 65:2712-2718. http://dx.doi. org/10.1139/F08-174

R Core Team. 2012. R: A language and environment for statistical computing. R Foundation for Statistical Computing, Vienna, Austria. [online] URL: http://www.R-project.org/

Roper, B. B., J. M. Buffington, S. Bennett, S. H. Lanigan, E. Archer, S. T. Downie, J. Faustini, T. W. Hillman, S. Hubler, K. Jones, et al. 2010. A comparison of the performance and compatibility protocols used by seven monitoring groups to measure stream habitat in the Pacific Northwest. North American Journal of Fisheries Management 30:565-587. http://dx.doi. org/10.1577/M09-061.1

Scrivener, J. C., and M. J. Brownlee. 1989. Effects of forest harvesting on spawning gravel and incubation survival of chum (Oncorhynchus keta) and coho salmon (O. kisutch) in Carnation Creek, British Columbia. Canadian Journal of Fisheries and Aquatic Sciences 46:681-696. http://dx.doi.org/10.1139/f89-087

Service, C. N., T. A., Nelson, P. C. Paquet, W. S. S. McInnes, and C. T. Darimont. 2012. Pipelines and parks: evaluating external risks to protected areas from the proposed Northern Gateway Oil Transport Project. Natural Areas Journal 32:367-376. http://dx. doi.org/10.3375/043.032.0404

Sharma, R., and R. Hilborn. 2001. Empirical relationships between watershed characteristics and coho salmon (Oncorhynchus kisutch) smolt abundance in 14 western Washington streams. 
Canadian Journal of Fisheries and Aquatic Sciences 58:1453-1463. http://dx.doi.org/10.1139/f01-091

Slaney, T. L., K. D. Hyatt, T. G. Northcote, and R. J. Fielden. 1996. Status of anadromous salmon and trout in British Columbia and Yukon. Fisheries 21:20-35. http://dx.doi. org/10.1577/1548-8446(1996)021<0020:SOASAT >2.0.CO;2

Smith, M., and A. Sterritt. [date unknown]. From conflict to collaboration: the story of the Great Bear Rainforest. Forest Ethics and Coastal First Nations, British Columbia, Canada. [online] URL: http://sfigreenwash.org/downloads/WWFpaper.pdf

Stouder, D. J., P. A. Bisson, and R. J. Naiman, editors. 1997. Pacific salmon and their ecosystems. Chapman and Hall, New York, New York, USA. http://dx.doi.org/10.1007/978-1-4615-6375-4

Suttle, K. B., M. E. Power, J. M. Levine, and C. McNeely. 2004. How fine sediment in riverbeds impairs growth and survival of juvenile salmonids. Ecological Applications 14:969-974. http://dx. doi.org/10.1890/03-5190

Sweeney, B. W., T. L. Bott, J. K. Jackson, L. A. Kaplan, J. D. Newbold, L. J. Standley, W. C. Hession, and R. J. Horwitz. 2004. Riparian deforestation, stream narrowing, and loss of stream ecosystem services. Proceedings of the National Academy of Sciences 10:14132-14137. http://dx.doi.org/10.1073/pnas.0405895101

Temple, N., editor. 2005. Salmon in the Great Bear Rainforest. Raincoast Conservation Society, Victoria, British Columbia, Canada. [online] URL: http://www.raincoast.org/files/ publications/reports/Salmon-in-the-GBR.pdf

Tschaplinski, P. J., and R. G. Pike. 2010. Riparian management and effects on function. Pages 479-526 in R. G. Pike, T. E. Redding, R. D. Moore, R. D. Winkler, and K. D. Bladon, editors. Compendium of forest hydrology and geomorphology in British Columbia. B.C. Ministry of Forests and Range, Research Branch, Victoria, British Columbia, Canada and FORREX Forest Research Extension Partnership, Kamloops, British Columbia, Canada. 


\section{Appendix 1}

This appendix contains the data cards developed by the Coastal First Nations — Great Bear Initiative for stream assessments by First Nations stewardship staff as part of their Regional Monitoring System stream assessment program. The cards include a Stream Transect card, Stream Assessment card, Stream Visit card, and Spawner Survey card.

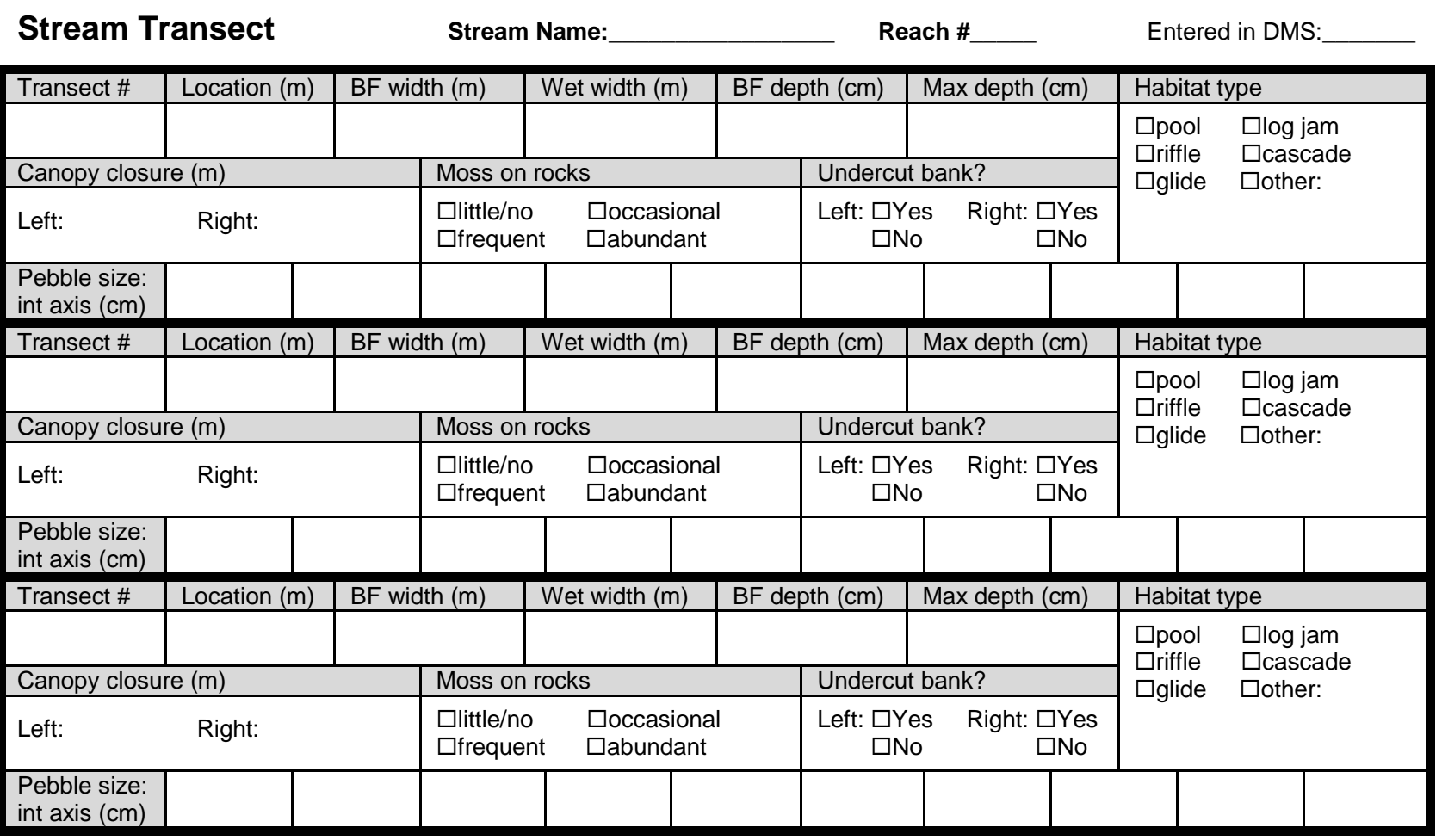

Fig. A1.1 - The Stream transect card used to record stream characteristics at multiple crosssectional transects within a reach. 
Stream Assessment (side 1)

Date:

Entered in DMS:

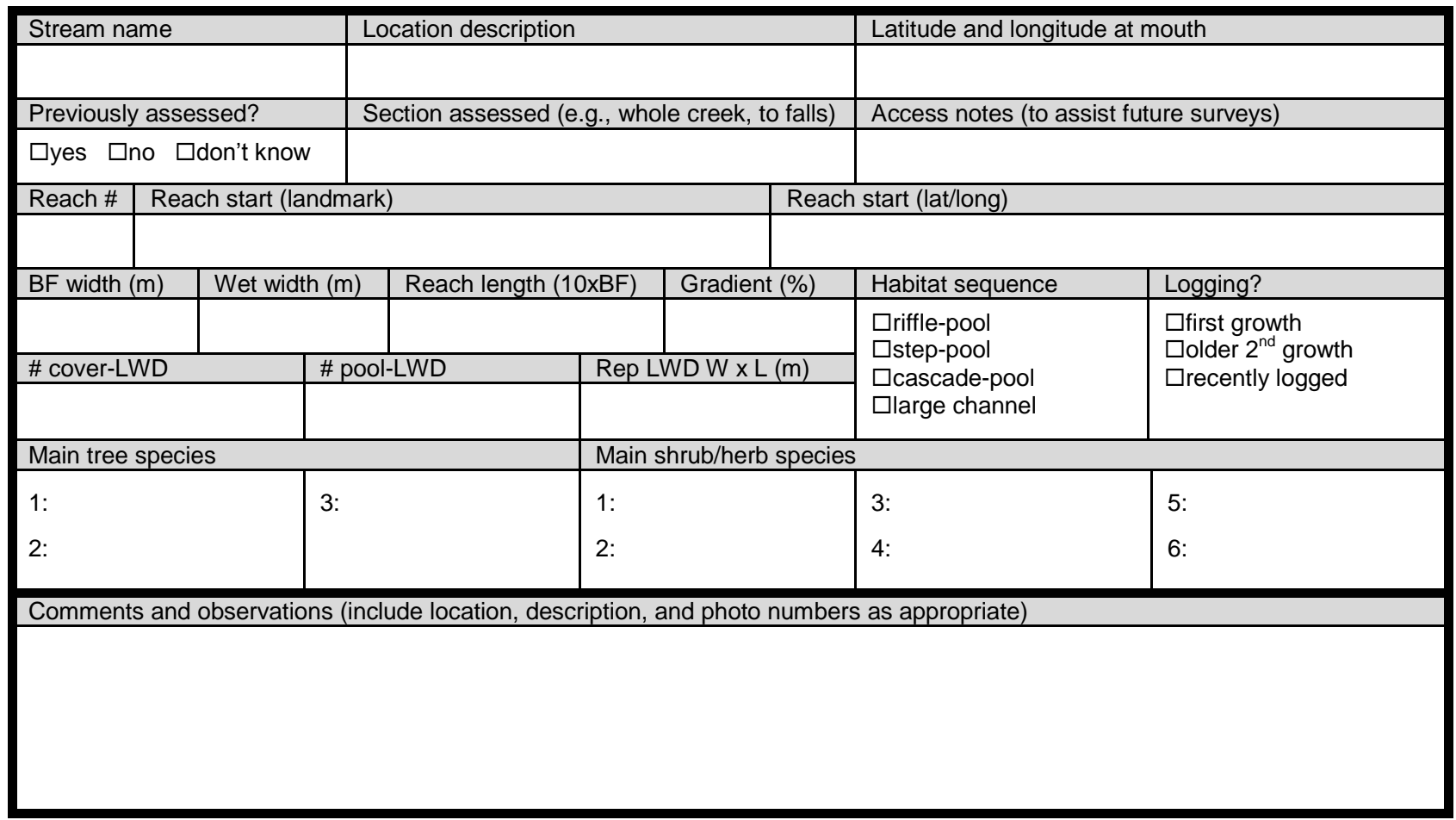

Fig. A1.2 - Side 1 of the Stream Assessment card used to record reach-level characteristics at each stream site. 
Stream Assessment (side 2)

Entered in DMS:

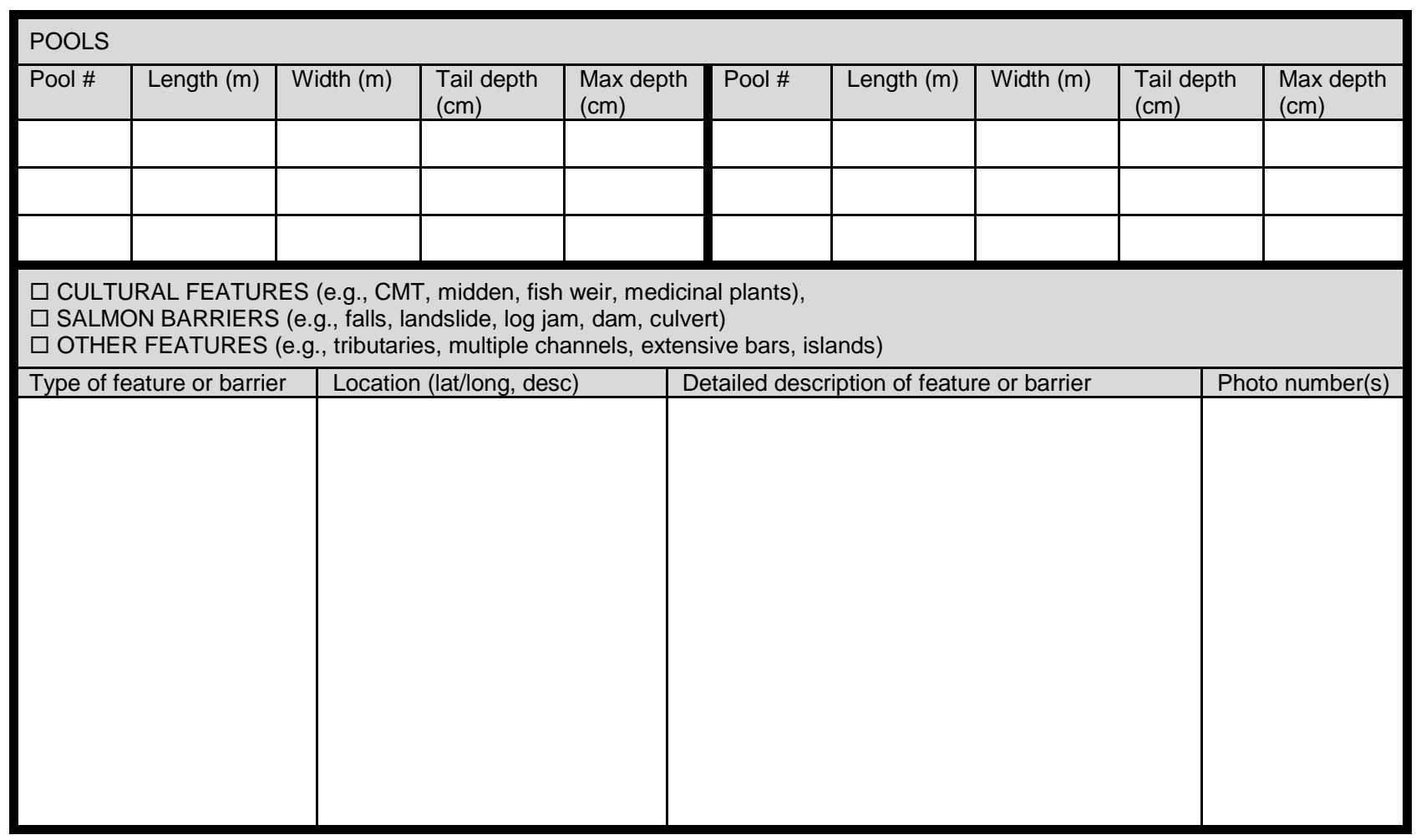

Fig. A1.3 - Side 2 of the Stream Assessment card. 
Stream Visit (v. 2)

Date:

Entered in DMS:

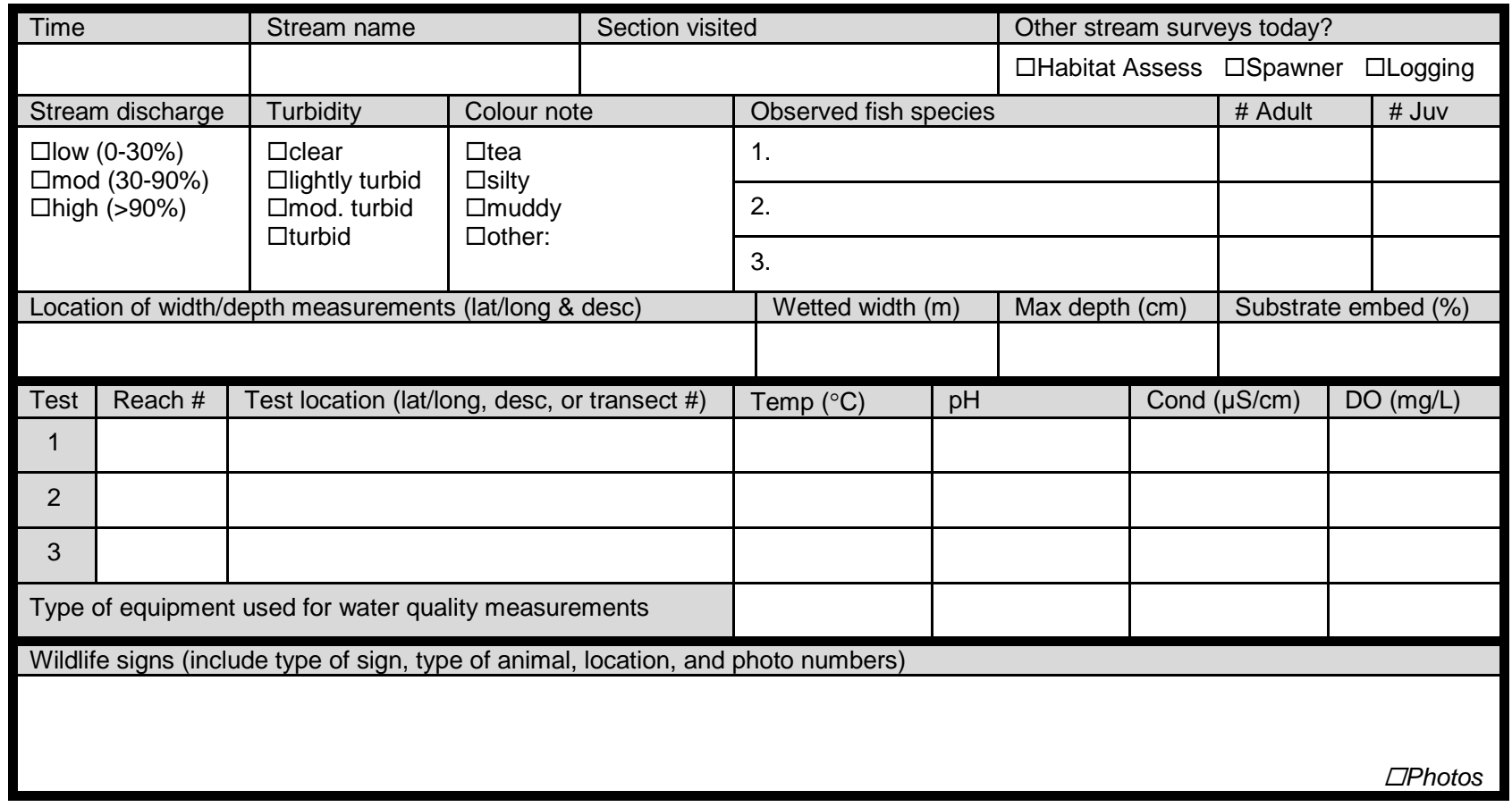

Fig. A1.4 - The Stream Visit card, which is to be used along with the Stream Assessment card and Stream Transect card, or individually if time does not permit a full assessment. 
Spawner Survey (v. 2)

Date:

Entered in DMS:

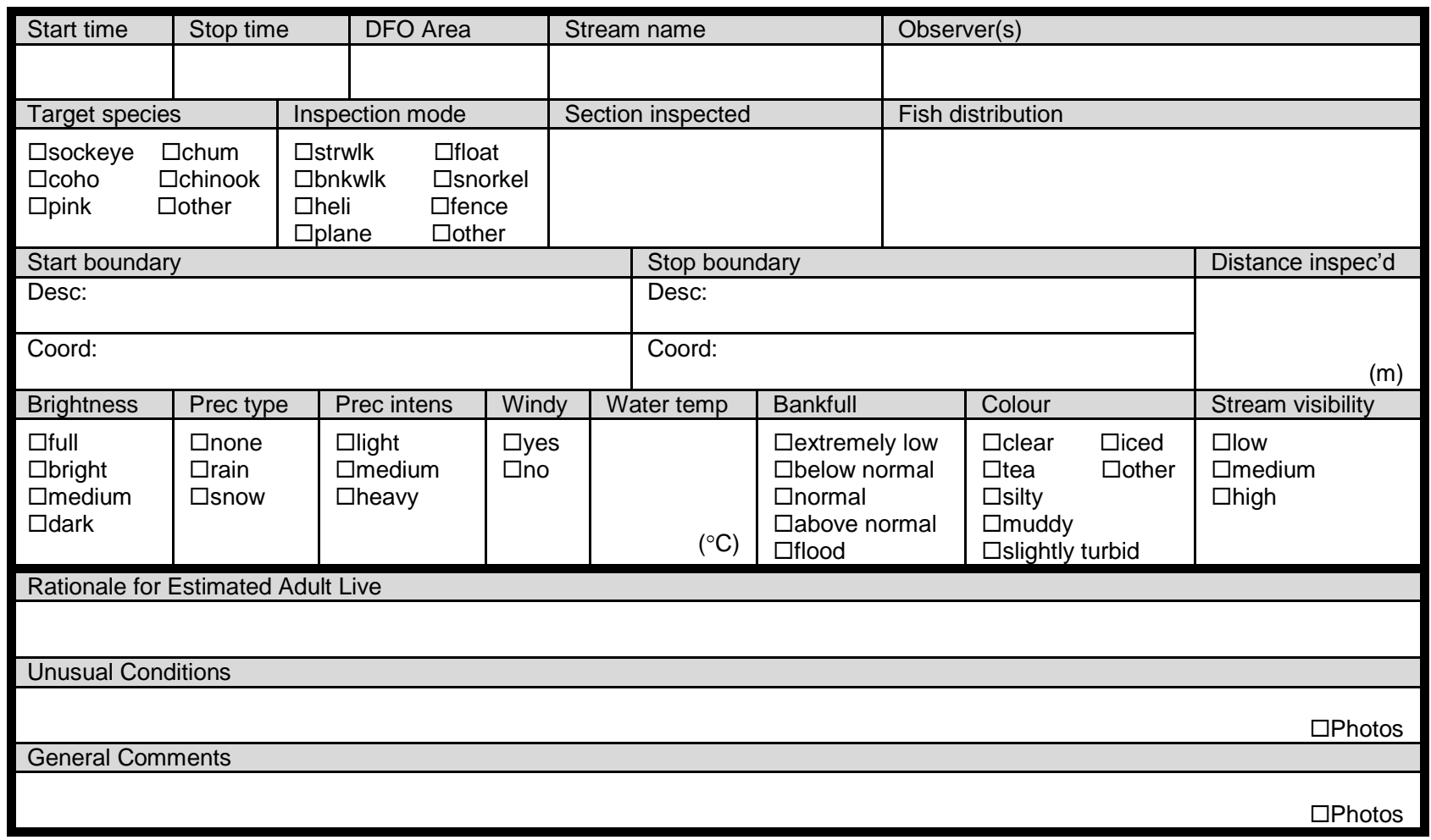

Fig. A1.5 - The Spawner Survey card, which is to be used to collect information on spawning salmon. 